Transactive memory and the job search:

Finding expertise and influence in socio-technical networks

Cameron W. Piercy ${ }^{1}$

Yaguang $\mathrm{Zhu}^{2}$

${ }^{1}$ Corresponding author, Assistant Professor, University of Kansas, Department of Communication Studies, cpiercy@ku.edu, 1440 Jayhawk Blvd., Room 102, Lawrence, KS 66045 ORCID: https://orcid.org/0000-0003-1431-3086

${ }^{2}$ Assistant Professor, University of Arkansas, Department of Communication, 417 Kimple Hall, Fayetteville, Arkansas 72701 ORCID: https://orcid.org/0000-0002-8025-3889 


\begin{abstract}
Structural, communicative, and relational attributes of transactive memory (TM) affect the expertise and influence job seekers perceive in their job information networks. Using a sample of U.S. job seekers $(\mathrm{N}=285)$, we found expertise and influence varied across structural attributes (both source status and bridging ability) and relational attributes (emotional closeness). Communicative attributes (communication frequency) were associated with influence, but not expertise. In addition, we found significant divergence in perceived influence across different sources. This study contributes to an understanding of job information networks, extends TM to a socio-technical context, and adds influence as a meaningful outcome of TM
\end{abstract}

Keywords: Transactive memory, expertise, influence, job search, network 


\section{Transactive memory and the job search: Finding expertise and influence in socio-technical networks}

Finding a job is a complex information seeking process whereby a job seeker calls on a wide variety of sources including close personal connections (e.g., friends and family), websites (e.g., indeed.com, monster.com), and formal sources (e.g., newspapers, employment agencies; Piercy \& Lee, 2019). Those who have access to best leverage network resources tend to find better jobs (Burt, 1995). On the one hand, job seekers need to locate sources with expert information (Granovetter, 1983). On the other hand, job seekers need to locate influential sources capable of advocating on their behalf or providing access to better jobs (Lin, Lee, \& Ao, 2014; Marin, 2012). However, little is known about how expertise and influence are identified and utilized in complex information resource networks. ${ }^{1}$ To fill in this gap, this study draws on Transactive Memory Theory (Wegner, 1987) to connect expertise and influence with structural, communicative, and relational antecedents of transactive memory (Treem \& Leonardi, 2017).

Transactive memory (TM) is a fundamentally communicative phenomena which focuses on the efficiency and effectiveness of encoding, decoding, retrieval, and storage of key information within a network (Peltokorpi, 2008). TM theory helps explain individual behavior, situated in complex information environments, in accomplishing a task (Treem \& Leonardi, 2017). Indeed, the basic premise of TM is that "one person has access to information in another's memory by virtue of knowing that the other person is a location for" a given resource (Wegner, 1987, p. 190). TM is a theory of network architecture, focused on "the emergence of knowledge networks" (Contractor, Monge, \& Leonardi, 2011, p. 709). TM focuses on how an actor's cognitive network translates into a communication network. Simply put, TM components like expertise are outcomes of perceived network properties. One type of information individuals 
may seek is expert information about job openings, culture, and pay. However, TM has not yet been applied to job seeking or the location of influence in a network.

In the job search context, TM represents the knowledge of "who knows what" and "who knows who." Some theories of job search (e.g., strength of weak ties, structural holes) have emphasized the importance of connections which bridge impassable boundaries (Burt, 2004; Granovetter, 1973). However, job seekers use a broad variety of social, formal, and technological sources to obtain jobs (Marsden \& Gorman, 2001; Piercy \& Lee, 2019). Within one's network, job seeking is an attempt to simultaneously identify sources with expertise (i.e., those with expert information about jobs) and influential sources (i.e., those with the ability to advocate on behalf of a job seeker or provide access to prestigious jobs; Lin, Ensel, \& Vaughn, 1981; Lin et al., 2014). Thus, in this study, we focus on the dual expertise and influence search in which job seekers engage, combining TM and job search studies.

Recent evidence suggests online resources are utilized to manage the uncertain job search process (Fetherston, Cherney, \& Bunton, 2018; Kramer, Lee, \& Guo, 2018). Following this evidence, we examine the sociotechnical networks — including human, technological, and organizational information sources - which job seekers use to locate the expertise and influence needed to obtain a job. We adopt the TM theoretical framework advanced by Treem and Leonardi (2017), to examine perceived antecedents of expertise and influence recognition across structural, relational, and communicative domains. Specifically, based on findings from both TM and job seeking research, this study (1) extends TM research to the relevant network task of finding a job and (2) unpacks job search research to incorporate influence as an outcome of TM. The following section briefly overviews TM, presenting competing justifications for expertise and influence recognition during the job search. 


\section{Transactive Memory}

Broadly, TM contends that information exists in two locations: inside individuals' minds and across a network of connections. Specifically, as Peltokorpi (2008) explains TM consists simultaneously of (a) "internal memory (what the individuals know personally), and (b) external memory (what the individuals collectively know about the knowledge of other members of their group or can be located and retrieved from other external storage devices)" (p. 379). When completing a task (e.g., finding a job), a TM system is created by integrating one's own experience and knowledge with perceptions that some connections hold valuable expertise. TM is both descriptive, detailing the knowledge structure and retrieval process, and prescriptive, demonstrating increased network accuracy and differentiated knowledge structures lead to success in network tasks (though almost exclusively in teams; e.g., Kotlarsky, van den Hooff, \& Houtman, 2015). This study focuses on the former goal, investigating expertise and influence recognition by job seekers.

Though TM theory was originally proposed to be a "property of a group" (Wenger, 1987, p. 191), subsequent research has expanded the scope of TM to organizational networks and online databases (i.e., Contractor et al., 2011; Sparrow, Liu, \& Wegner, 2011; Treem \& Leonardi, 2017). In all, TM is predicated on a network of individuals working in concert to coordinate knowledge (Yuan, Fulk, Monge, \& Contractor, 2010). This study embraces the view that TM functions as a process whereby an actor's (i.e., job seeker's) perceptions that others possess knowledge or expertise prompts networked action (Kotlarsky et al., 2015). Calling on job seeking research, we propose that influence is also a meaningful outcome of TM. Finally, grounded in Contractor et al.'s (2011) theorizing, we acknowledge that networks of expertise and 
influence are composed of multiple sources of information: people, organizations, and technologies.

\section{Transactive Memory Beyond Groups}

Expertise serves as a valuable asset in determining the sources actors utilize in completing tasks (Contractor et al., 2011). TM theory predicts network connections, or alters, that are perceived to have more knowledge or expertise will be utilized more often (Wegner, 1995). Studies show information from an alter with technical expertise will be favored over an alter with less expertise, even in networks composed of both humans and technological actors (Yuan et al., 2010). Expertise is essentially a "social, dynamic, and interactive" commodity increasingly exchanged via information and communication technologies across organizational and team settings (Kotlarsky et al., 2015, p. 337). Job search serves as a viable testing ground for the attainment of expertise through multifarious social and technical sources.

Though TM focuses on expertise, job search research demonstrates influence is also important in job attainment (Burt, 1992; Lin et al., 1981; Granovetter, 1983). Both job search and TM research often focus on the resources available in a network, or social capital (Putnam, 2000). For this reason, findings from job search research are well-situated to contribute to understandings of TM networks. Specifically, job search research often focuses on both information and influence as important network outcomes; whereas, TM generally highlights expertise alone.

Both expertise and influence are forms of social capital that can be expected as a return from maintaining a variety of social relationships (Lin, 2001). Thus, who a job seeker knows, that alter's knowledge, and the alter's ability to influence on behalf of the job seeker are equally important. In TM terms, job seekers need not only those who hold knowledge but also 
individuals who can effectively encode, decode, and communicate with others to aid the job search process (Monge \& Contractor, 2003). Therefore, in addition to expertise recognition, this study proposes that TM networks can be observed in the identification of influential alters.

Structure and TM. Treem and Leonardi (2017) propose three factors that may affect expertise recognition in TM systems: structural, relational, and communicative influences. Structural influences have to do with the configuration of networks. In the job search context, structural influences include network locations and status differences. For instance, Lee and colleagues (2019) find that hierarchical position affects who talks to whom to receive social support. Network properties including power differences, network closure, and structural positions all affect whom one turns to when seeking knowledge and influence during a job search.

Though the use of social contacts shows no benefit in job attainment relative to traditional/formal sources, the use of higher status contacts leads to better job attainment (Marsden \& Gorman, 2001). Broadly, research suggests both being connected and having contacts with higher status positively relates to job attainment (Van Hoye, van Hooft, \& Lievens, 2009). A classic finding, replicated across studies, is that alter's status positively relates to increased status in job attainment (Lin, Ensel, \& Vaugh, 1981; Lin et al., 2014). Contacts with higher status than the job seeker provide access to better job information than lower status alters.

In TM, those with differential status may offer expertise which job seekers are unable to find elsewhere. Recognizing status is a cue that expertise is available via a source. In line with Lin et al. (1981), high status sources can also provide more influence. Thus, we propose that social status relates to both a source's expertise and influence:

H1: Perceived source status is positively associated with perceived source expertise 
during the job search.

H2: Perceived source status is positively associated with perceived source influence during the job search.

Having a broader network leads to higher accuracy in network perception; in fact, those who are more highly connected recognize expertise more readily (Peltokorpi, 2008). In addition, TM research shows locating key resources in one's network is associated with changes in the network over time (Lee, Bachrach, \& Lewis, 2014). Given the range of evidence viewing the job search as a network process (Granovetter, 1983; van Hoye et al,, 2009), using TM to explain job search behaviors is a natural fit. In all, finding a job is a highly interdependent task whereby individuals share (or withhold) knowledge to assist each other in obtaining employment.

Triadic closure, or higher levels of alters knowing one another, has been positively associated with TM in network research (Lee et al., 2014). The job seeking research considers closure, or the saturation of one's network with strong ties, as limiting the dispersion of novel or unique job information (Granovetter, 1973). Thus, TM and network theory offer competing justifications for turning to different sources of job information. While network theory would suggest that expertise is a property of a loosely connected network (due to alters' ability to access novel information; Burt, 2004; Granovetter, 1983), TM theorizing emphasizes the importance of interconnectedness (or triadic closure; Peltokorpi, 2008). Thus, we ask:

RQ1: What is the relationship between network closure and perceived expertise of sources utilized?

RQ2: What is the relationship between network closure and perceived influence of sources utilized? 
Job search research contends weak social connections are valuable because of their ability to bridge to otherwise disconnected portions of a person's network (Granovetter, 1973). Bridging capital, was originally thought to be an attribute of weak social ties, or those whom one does not know well; whereas, bonding capital, which includes emotional support, advice, or access to resources, was generally associated with close connections (Putnam, 2000). However, network research clarifies that any contact who is capable of connecting a job seeker with information that would otherwise be inaccessible offers bridging capital, regardless of tie strength (Burt, 1995; 2004; Granovetter, 1983). So, modern network theory predicts that bridging connections can aid or withhold information and influence (see Burt's [1995] discussion of tertius). Expertise experts point out that bridging ability is related to successful knowledge attainment (Treem \& Leonardi, 2016). Thus, the relationship between a source's bridging ability and expertise is likely positive, while the relationships between bridging and influence remains unknown. Therefore, we pose the following:

H3: Perceived bridging ability is positively associated with perceived source expertise during the job search.

RQ3: What is the relationship between perceived bridging ability and perceived source influence during the job search?

Communication and TM. The second catalyst for expertise recognition in the TM job search is communication dynamics. TM is facilitated by communication and relational properties (Hollingshead, 1998). Initially, frequency of communication has been associated with increased expertise recognition among leadership trainees (Treem \& Leonardi, 2017) and higher information recall among strangers and romantic partners (Hollingshead, 1998). This paper adopts Treem's (2012) communicative view of expertise as "an attribution that emerges through 
social interaction and is communicated to others through the process of organizing” (p. 25). Thus, interaction frequency ought to relate to expertise attributions:

H4: Frequency of communication interaction is positively associated with perceived source expertise during the job search.

Evidence is mixed regarding the relationship between influence and communication frequency. Granovetter (1983) contends that more frequent communication partners are more likely to exert influence in the job attainment process. A central premise of network research is: Strong connections, those whom one interacts with frequently, are more likely to take action on behalf of an actor (Burt, 2004).

However, frequent communication partners are often unwilling to advocate on behalf of a job seeker. Marin (2012) and Smith (2012) both find the social cost incurred by sticking one's neck to aide in job attainment is high: It can reflect poorly on the recommender if a referral is an inept worker. Smith (2012) finds that job information holders are more willing to follow-up on applications submitted by relative strangers, as compared to friends and family. Those who we interact with frequently are not uniformly likely to advocate on behalf of a job seeker. Therefore, we ask:

RQ4: What relationship, if any, is there between frequency of communication interaction and influence?

Relationships and TM. Relational attributes, like strength of relationship, may also drive the relationship between expertise perception and source utilization. For instance, Hollingshead (1998) found that romantic couples counted on each other more during a shared information task than did strangers. Stronger ties provide knowledge that is more tacit and less easily articulated or transferred (Yuan et al., 2010). Indeed, stronger connections are needed to accomplish 
difficult tasks in which information is difficult to articulate or acquire (Granovetter, 1983). This evidence is complimented by TM theorizing which posits interpersonal attraction increases the likelihood of knowledge sharing (Wegner, 1987). Therefore, we hypothesize:

H5: Emotional closeness is positively associated with perceived source expertise during the job search.

The relationship between emotional closeness and influence is more fluid. Because tie strength is often considered an amalgam of emotional closeness and frequency of interaction (Granovetter, 1973), the logic for relating emotional closeness and influence mirrors that for frequency of communication. When it comes to recommending a contact, the findings by Smith (2012) and Marin (2012) suggest that close alters are often not willing to assist job seekers. Smith contends many participants were eager to share information with those who they did not know well, but were reticent to share with close friends. However, network research generally finds those with whom one is close are likely to exert influence (Granovetter, 1983). Strong personal ties can carry the costs of conveying information to employers, and the costs associated with "sticking their necks out" and even "serve[ing] as advocates" (Marsden \& Gorman, 2001, p. 470). Following the majority of evidence, we propose:

H6: Emotional closeness is positively associated with perceived source influence during the job search.

\section{Variation among Types of Sources}

Finally, job seekers utilize a complex socio-technical network and use a wide-variety of sources (Piercy \& Lee, 2019). In TM theorizing, the encoding process of key information sources is critical to the formation and maintenance of the TM system (Hollingshead, 1998; Lee et al., 2014). The attainment of job information from different sources helps foster TM 
perceptions. Some evidence suggests that human and technological sources are used differently depending on the nature of the task (e.g., Contractor et al., 2011); yet, sociotechnical sources are oftentimes utilized in conjunction when finding a job (Fetherston et al., 2018; Piercy \& Lee, 2019). As Treem and Leonardi (2016) succinctly explain, "Technologies are part and parcel of expertise. They enable individuals to trade certain kinds of knowledge...to view people's actions and make attributions about the expertise of others" (p. 16). Each alter enables users to make impressions of expertise and influence, the question remains to whom or what are expertise and influence attributed. Is a friend who suggests or discourages a position perceived as more expert than a website with wonderful (or terrible) reviews of an organization? The variations in expertise and influence across sources remains underexplored in job search. Thus, we ask:

RQ5: How do sources differ in terms of (a) expertise and (b) influence?

\section{Method}

\section{Participants}

Study participants were recruited via Amazon Mechanical Turk (MTurk). Two screener questions established participants lived United States and had sought a job within the past twoyears. Participants were paid $\$ 5.00$, for their participation in this study as part of a larger research project. MTurk convenience samples have shown comparable reliability to students and professional panels (Sheehan, 2017). However, MTurk better represents the population than a student sample. Consistent with best-practices research (Rouse, 2015), participants were required to verify their attention via four attention checks (e.g., "I am paying attention so I will select strongly agree."). Participants who failed three or more attention checks were not paid and their data was not used in analysis. The final sample includes 285 participants who were either seeking a job or had done so in the previous two years. Participants answered an open-ended 
question about their occupation and came from a wide variety of industries representing both blue- and white-collar work.

Participants ranged in age from 19 to 62 years old $(M=35.86, S D=9.03$, Med. $=34)$. Slightly under half $(47.7 \%)$ of participants $(n=136)$ were female. Most participants had a college degree $(n=182,63.9 \%)$, while $103(36.1 \%)$ had a high school degree or less. Eightythree percent of participants were Caucasian $(n=246)$. One hundred twenty-eight participants (44.9\%) reported a household income of less than $\$ 40 \mathrm{~K}$ per year, $76(26.9 \%)$ between $\$ 40 \mathrm{~K}$ and \$70K per year, $79(27.7 \%)$ earned more than $\$ 70 \mathrm{~K}$ per year, and two participants $(0.7 \%)$ did not answer. Participants came from 42 different U.S. states. The majority of participants were currently employed $(n=228,80 \%)$. Still, most participants $(n=197,69.1 \%)$ were definitely or probably looking for a job at the time of the study.

\section{Measures}

Network closure. We utilized McCarty, Killworth, Bernard, Johnsen, and Shelley's (2001) relational categories to collect network data. Exploratory factor analysis (EFA) revealed strong and weak tie dimensions. Strong ties included: immediate family, family of spouse/partner, best friends/confidants, neighbors and just friends. These strong ties held together fairly reliably, Cronbach's $\alpha=83$. Weak ties included: people at work who you don't directly work with, people from other organizations, people know through others, people who provide a service, and other people. This sub-scale was reliable, Cronbach's $\alpha=.78$.

RQ1 and RQ2 focus on closure, higher levels of connection among alters. Closure was calculated by taking the proportion of strong ties (who are likely to know one another; Burt, $2005)$ relative to the total number of ties in one's network. Because strong ties are more likely to know one another (e.g., one's best friends or parents typically know one another), this is a 
reasonable proxy for triadic closure in the absence of whole-network data. In line with Granovetters (1973) we anticipate strong ties exhibit closure whereas weak ties are unlikely to exhibit closure. The strong tie scale was divided by the total number of relations (strong ties plus weak ties) to create a proportion of strong-to-weak ties, or closure. This value ranged from 0.03 to 1.00 , where 1.00 represents a network composed entirely of strong ties $(M=0.35, S D=0.17)$.

TM Attributes. For the remaining scales, participants initially identified the sources they used by name using a check-list of ten sources, close friends or family members contacted online and in person, acquaintances or professional contacts online and in person, websites, direct inperson applications, direct online applications, career events, job boards/listservs, and employment agencies (see Table 4). The names participants entered (e.g., Bill, glassdoor.com, Express Employment Services) were used to populate subsequent questions. For instance, if participants used four (of the ten) sources, they answered the subsequent scales four times. The survey design logic presented each source in a random order; additionally, within each source the scales (detailed below) were randomized. Truncated scales were used when possible to reduce participant fatigue.

Expertise. Existing TM measures focus on team performance. For this study, the competence factor of McCroskey and Teven's (1999) scale of source credibility was adapted to assess individuals' perceived source expertise. This scale is concise and easy to rate on six 7point semantic differentials scale: inexpert/expert, intelligent/unintelligent, untrained/trained, informed/uniformed, incompetent/competent, bright/stupid. The scale was reliable (Cronbach's $\alpha$ $=.94, M=5.60, S D=1.08)$.

Influence. To measure influence, we adapted a modified version of Anderson, John, and Keltner's (2012) sense of power scale. Respondents indicated their degree of agreement on a 7- 
point scale (Strongly disagree $=1$; Strongly agree $=7$ ) about how capable a source was of influencing others. Consistent with Anderson et al.'s (2012) conceptualization of the scale, the scale was adapted to focus on perceived power of others. Participants responded to seven questions including: "[Source]'s wishes do not carry much weight with a hiring organization," and "I think [source] has a great deal of power over a hiring organization." The scale was reliable, Cronbach's $\alpha=.94,(M=4.35, S D=1.51)$.

Source Status. The subjective social status scale was adapted to measure social status. This scale has demonstrated internal and external validity in previous studies (e.g., Operario, Adler \& Williams, 2004). Participants were given an image of 10-rung ladder with the prompt: Think of a ladder with 10 steps representing where people stand in US society. At step 10 are the best off - those who have the most money, the most education, and the most respected jobs. At step 1 are the worst off - those who have the least money, least education, and the least respected jobs or no job. Where would you place [source name]/the people who contribute to [source name] on the ladder? $(M=6.10, S D=1.74)$.

Bridging ability. To assess bridging ability, we developed a new scale based on existing literature. Bridging is often operationalized as a network property (for details see, Burt, 1995). However, the concept of bridging is well-defined in network research as the ability to connect with otherwise inaccessible network resources. We asked participants to rate their agreement with five statements via a 7-point scale (Strongly disagree $=1$; Strongly agree $=7$ ): "[Source] is capable of connecting me with information I could not otherwise access," "[Source] serves as an intermediary between myself and the job I sought," "[Source] is not able to connect me with potential employers," "[Source] is not capable of connecting me with others who have valuable information about the job I sought," and "[Source] is connected to employers who I could not 
access otherwise."

A confirmatory factor analysis was conducted using the R package lavaan (v. 0.6-3;

Rosseel, 2012) to validate of this scale. Using the DWLS estimator, this scale initially had a poor fit: $\chi^{2}(5)=211.91, p<.001, \chi^{2} / d f=42.38, \mathrm{RMSEA}=.18,90 \% \mathrm{CI}[.16, .20], \mathrm{SRMR}=.06, \mathrm{CFI}=$ 0.99. However, the fit improved significantly $\left(\Delta \chi^{2}(3)=201.54, p<.001\right)$ when the fourth item, which loaded poorly on the latent $\left(R^{2}=.29\right)$, was excluded: $\chi^{2}(2)=10.37, p<.001$, RMSEA $=$ $.06,90 \% \mathrm{CI}[.03, .09], \mathrm{CFI}=1.00, \mathrm{SRMR}=.02$. The final scale was reliable, $M=5.19, \mathrm{SD}=$ 1.20 , Cronbach's $\alpha=.81$.

Frequency of Interaction. Interaction frequency was assessed by asking participants how often they interacted with a given source during the course of job search. Specifically, we used a scale adapted from Granovetter's (1973) seminal research: 1 = never, 2 = once a year, 3 = several times a year, $4=$ every few months, $5=$ monthly, $6=$ weekly, $7=$ several times a week, $8=$ daily $(M=5.56, S D=1.76)$.

Emotional Closeness. Emotional closeness was measured using the inclusion of other in the self (IOS) scale. IOS has high convergent and discriminant validity (see, Gätcher, Starmer, \& Tufano, 2015). IOS uses a single-item pictorial representation of the other and self as progressively overlapping circles. Past research has used this as an indicator of relational strength (e.g., Rozzell et al., 2014). Participants were given the following prompt: "Please select the picture that best describes your current relationship with [source]." The grand mean was 3.34 $(S D=1.70)$, signaling a moderate amount of closeness. Table 1 presents means, and standard deviations, and correlations among key study variables.

\section{Analysis}


General linear model (GLM) procedures assume an independence of observations/errors. Measuring the same items, for each source, from the same participant several times violates the assumption of independent measurement. This nonindependence between ego and alters is commonly called network autocorrelation. To account for network autocorrelation, we employed a multi-level model (MLM) with fixed effects for the specified hypotheses and random effects were specified for participants and sources. These random effects served as significant controls in both the expertise (ICC $=0.34)$ and influence $(\mathrm{ICC}=.29)$ models. Specifically, we used the R package 'nmle' (Pinheiro, Bates, DebRoy, Sarkar, \& R Core Team, 2018).

These MLMs control for both participants' repeated responses and source types. Controlling for participants both corrects for nonindependence in the data as well as for any potential respondent characteristics, such as age, education, gender, and job tenure. Similarly, controlling for source-type permits us to test how perceived expertise and influence relate to the predicted antecedents across sources. Separate models were computed for each outcome variable: expertise and influence (see Tables 2 and 3, respectively). Predictors were entered in the MLMs one at-a-time to test for significant changes in the likelihood ratio test (LRT; the build-up method).

Insert Table $2 \& 3$ here-

\section{Results}

H1 hypothesized source status would be positively related to expertise. This was supported by improved model fit, $\chi^{2}(1)=262.96, p=.000$, and the predictor remained significant when accounting for all relevant relationships (Estimate $=0.22, S E=0.02, t(1288)=14.69)$. Thus, H1 was supported. In parallel, H2 predicted source status would be positively related to influence. This was supported by the LRT, $\chi^{2}(1)=160.35, p=.000$, and the fixed effect in the 
final model $($ Estimate $=0.22, S E=0.02, t(1288)=10.44)$. Thus, $\mathrm{H} 2$ was supported. Status of the job information source was positively related to both expertise and influence.

RQ1 asked what relationship, if any, existed between network closure and expertise. Closure was not a significant predictor of expertise, with no significant change in model fit $\left(\chi^{2}(1)\right.$ $=0.94, p=.33)$. RQ2 asked what relationship existed between network closure and influence. Closure was not a significant predictor of influence, it did not improve model fit $\left(\chi^{2}(1)=0.17, p\right.$ $=.68$ ) and was not a significant predictor. Thus, the answer to RQ1 and RQ2 is that closure was not related to perceptions of either expertise or influence.

$\mathrm{H} 3$ predicted perceived bridging ability would positively relate to expertise. Results show that the model fit improved when adding bridging ability $\left(\chi^{2}(1)=165.66, p=.000\right)$, and remained significant in the final model $($ Estimate $=0.26, S E=0.02, t(1288)=13.09) . \mathrm{H} 3$ was supported. In parallel, RQ3 asked what relationship was present between perceived bridging ability and influence. Adding perceived bridging significantly improved model fit, $\chi^{2}(1)=$ $141.02, p=.000$ and significantly predicted influence: Estimate $=0.37, S E=0.03, t(1288)=$ 12.90. Perceived bridging ability was positively related to both expertise and influence.

H4 predicted interaction frequency would be positively related to expertise. The model showed no significant relationship between expertise and interaction frequency, $\chi^{2}(1)=2.01, p=$ .157. Thus, H4 was not supported. RQ4 asked what relationship, if any, existed between perceived influence and interaction frequency. The model showed a significant positive relationship between influence and interaction frequency: $\left(\chi^{2}(1)=20.10, p=.000\right.$, Estimate $=$ $0.14, S E=0.03, t(1288)=5.38)$. Thus, the answer to RQ4 is interaction frequency positively predicts influence. 
H5 predicted emotional closeness would positively predict ratings of perceived expertise. Results showed significant model improvement $\left(\chi^{2}(1)=40.44, p=.000\right)$ and emotional closeness was positively related to expertise ratings (Estimate $=0.12, S E=0.02, t(1288)=6.45)$. Thus, H5 was supported. H6 predicted emotional closeness would positively predict perceived influence ratings. Results showed that the model significantly improved $\left(\chi^{2}(1)=7.57, p=.006\right)$ and emotional closeness was positively related to perceived influence (Estimate $=0.07, S E=$ $0.02, t(1288)=2.77)$. Thus, H6 was supported.

The final research question, RQ5, asked how different types of sources varied in terms of expertise and influence. To answer this question, two ANOVAs using sources as the grouping variable and expertise and influence, as the dependent variables were computed.

The ANOVA with expertise as the dependent variable was computed first. Results showed significant differences across source type: $F(9,1287)=4.06, p<.001, \eta^{2}$ partial $=.03$. Means and standard deviations are presented in the third and fourth columns of Table 4. Post hoc analyses using the Bonferroni correction showed four significant differences between weak ties contacted online and in person and websites and job boards. Broadly speaking, weak ties were rated as more expert than were these two online sources.

A second ANOVA was computed using source as the grouping variable and influence as the dependent variable. Results showed a significant main effect: $F(9,1287)=33.10, p<.001$, $\eta^{2}$ partial $=.19$. Post hoc tests revealed significant differences between many types of sources, (see fifth and sixth columns in Table 4). Broadly two trends emerged in the comparison: (1) direct application online and in-person were rated as very influential and (2) websites and job boards were rated as the least influential. Specifically, direct online application was rated as more influential than strong ties (online and in-person), websites, and job boards; further, direct in- 
person application was rated as more influential than those same sources as well as career fairs. Websites and job boards were significantly less influential than all other sources. The answer to the final research question is that weak ties were perceived as the most expert. In contrast, the most influential sources were direct application sources, while the least influential were websites and job boards.

Insert Table 4 here-

\section{Discussion}

Finding a job is a complex information seeking task whereby job seekers must locate job information expertise and seek influential sources. This study reveals the network correlates of TM theory in job searches. Further, this study uses the novel context of job search to explore TM theory in the network of socio-technical job information. Results show that expertise and influence are related to structural (i.e., source status, perceived ability to bridge), communicative (i.e., frequency of communication), and relational (i.e., closeness) domains of TM. Further, examination of source differences (RQ5) reveals that different sources were perceived to offer similar levels of expertise but vary in ability to influence.

These findings inform both TM and network theories relative to the job search. Initially, the socio-technical extension of TM theory (Contractor et al., 2011) can be better understood in the complex information environment of job searching. Websites and job boards/lists were perceived as less expert and less influential than social sources. Direct applications and weak ties were considered most influential. This should be considered in the context that more than nine in ten job seekers in this study used websites (see, Table 4). Network theory would contend the ubiquity of online information, in terms of both quantity and accessibility, signals a reduction in information value (Bruggeman, 2016). To wit, if the value of source decreases with increased 
use, job seekers ought to be skeptical of information posted broadly online relative to hard-toaccess information (e.g., Monster.com vs. messaging a friend).

At the same time, given the high use of websites, lack of influence does not appear to impede source utilization. Further, participants did not distinguish mode of communication and communication partner (i.e., strong or weak connection on and offline) in terms of information and influence. In other words, the sources job seekers utilize are not necessarily those which are particularly expert or influential. The use of technology is, instead, part and parcel of the expertise (and influence) location process (Treem \& Leonardi, 2017).

Locating expertise in one's network during a job search is a function of source status, bridging ability, and one's closeness with the source. Surprisingly there was no relationship to network closure or interaction frequency. Though closure has demonstrated meaningful effects on team TM (Lee et al., 2014), in this study, our measure of closure did not relate to expertise. This is compounded by ample evidence in network science suggesting that closure impedes information flow (Burt, 1995). Source status remains an important correlate of expertise (Lin et al., 1981). Additional research on job search outcomes could explore how the use of more (or less) expert sources leads to differences in job attainment, pay, and other relevant outcomes.

Sparrow et al. (2011) boldly claim that TM systems have generated a "symbiotic" relationship between network actors and online information sources (p. 778). In the rich network context of job search, job seekers are turning to online sources for information and influence. Further, they likely do so while trading off time spent with peers and colleagues. Though our evidence is correlational, not causal, these results suggest that turn to the internet when they need to find work. Further, websites and job boards provide a high-level of expertise (like all other sources), but are perceived to lack the ability to influence. Perhaps job seekers ought to focus on 
sources who can influence in the job search process (Lin et al., 1981; 2014). But job seekers should also consider the growing evidence suggesting strong social connections are not likely to intervene on behalf of job seekers (i.e., Marin, 2012; Smith, 2012).

Though Kwahk and Park (2018) contend that transactive memory is improved via social media use, our study shows statistically indistinguishable differences in expertise and influence for ties contacted on and offline. This supports past evidence that tie variety is superior to tie type when considering which sources to use during a job search (Gee et al., 2017; Piercy \& Lee, 2019). Put simply, diverse sources offer differentiated influence which compliments these recent job search findings. However, knowledge or expertise is perceived quite uniform across sources used. For job seekers and job search coaches, turning to additional types of sources (e.g., not just weak ties), and influential sources (i.e., employment agencies, direct applications, and weak ties) may offer greater benefits (Lin et al., 2014). Our study is centered on network composition, future studies should combine network composition with job attainment and person-job fit.

Another meaningful correlate of expertise and influence is perceived bridging ability. This suggests that individuals value the ability of their network members to connect with otherwise inaccessible opportunities and information. Indeed, in the influence model, bridging yielded the highest estimate. This study fulfills the call to examine "both dyadic (e.g., strength of tie, reciprocal exchange) and triadic (e.g., transitive) information exchanges" in TM systems (Lee et al., 2014, p. 963). However, our findings differ, while Lee and colleagues found that triadic closure affected TM, only dyadic traits (closeness) and structural source attributes (status, bridging) related to expertise in this study. Certainly, our ego-network measures are different from whole-network data collection methods. This null relationship might occur for two reasons: (1) our measure of network closure is derived from participants perceived network which may 
limit the measure's validity and (2) it is possible that the countervailing effects of brokerage and closure, predicted by TM and job search research, could both be at work. These competing predictions about the role of closure are a rich area for future research.

Contrasting sources (RQ5), Granovetter's (1983) claim that weak social connections offer the most novel information was partially supported. Weaker ties (i.e., acquaintances and colleagues contacted online and in person) were perceived to have greater expertise than websites and job boards. However, when it comes to influence, job seekers were more likely to perceive greater influence through direct contact with an organization than through strong ties (though no differences emerged between social ties). This evidence adds nuance to the strength of weak ties (SWT) hypothesis, showing that weak ties provide both expertise and influence, relative to other sources. TM theory should continue to explore indicators of relational strength as an important predictor of expertise transfer (e.g., Hollingshead, 1998). Again, we suggest that job seekers consider not just tie strength but also ties' influence and bridging ability in deciding which sources to devote limited time, energy, and effort during the job search.

Though this study supports some tenants of SWT, the models predicting perceived expertise and influence show that frequency of interaction and closeness have differentiated effects. These findings challenge the assumption that tie-strength is a linear combination of emotional closeness, frequency of interaction, intimacy, and reciprocity (Granovetter, 1973). Expertise and influence are differentially predicted by frequency of interaction and closeness. While both predicted influence, only closeness related to expertise. Frequency of interaction positively predicted perceived influence and was unrelated to expertise. Some of this relationship is likely attributable to variation in the size and direction of the correlations between 
different attributes and influence across sources. However, the MLM yields robust findings controlling for both source-type and participant effects.

A central premise of TM is that interaction frequency ought to relate to identification of expertise in one's network (Peltokorpi, 2008; Treem, 2012). Future research should tease out potential reasons why interaction frequency was unrelated to expertise. Perhaps personality (e.g., extraversion, uncertainty), demographic traits (e.g., tenure, age), or order effects for the expertise-interaction relationship could explain this unexpected finding. Future research can benefit from using varied measures of networked interactions and psychological attributions beyond 'tie strength.' It is likely that job seekers feel they cannot approach high-status, expert sources. Job seekers may benefit from knowing that those expert and influential sources offer more success in the job attainment (Lee et al., 2014), and be encouraged to seek those resources.

Emotional closeness was positively associated with both expertise and influence.

Generally, emotional closeness is considered an attribute of strong ties (Granovetter, 1983). The relationship with emotional closeness should be considered in the context of source type: websites and formal sources (e.g., career fairs, employment agencies) are likely to be perceive less close than social connections (strong or weak). Thus, this finding also informs TM systems composed of socio-technical sources. These findings suggest expertise is best thought of as an attribute of social connections, especially weak ties. Consistent with research on online social capital acquisition during the job search (e.g., Gee et al., 2017), weak social connections remain important to job seekers' TM network. Though canonical work on the effects of the Internet-use on community suggest reduced social connection (i.e., Putnam, 2000), social ties remain important sources of expertise (on and offline). 
Extending TM to include influence, a key component of the formation and maintenance of a job search networks, is a both a theoretical and practical contribution of our study. Traditionally TM research has been limited to outcomes associated with the transfer of knowledge and expertise. However, meaningful effects of transactive antecedents and influenceoutcomes are demonstrated in this study. TM theory ought to include additional meaningful outcomes of networked information, influence, and other relevant stores of information (e.g., support). Further, our finding speaks directly to the practical strategy of job seeking. Job seekers need to learn how to cultivate professional relationships and properly leverage the influence of those connections in landing jobs. Influential ties are often the gatekeepers to new opportunities and every job seeker will benefit from finding ways to leverage both their expertise and influence. Further, to the extent that TM applies beyond expertise acquisition (and within the job search) this theory can be useful for individuals, coaches, and practitioners who seek to leverage resources in the network (e.g., locating support after a loss, finding a loan in a difficult time).

Indeed, there was significant divergence in ability to influence across various sources of job information. Overall, websites and job boards/lists appear to be the least influential and direct contact with organizations (in-person and online) were the most influential. This suggests that job seekers perceive sources that allow them to feel personally (rather than vicariously) efficacious as the most influential. The role of efficacy in job attainment is well documented (Fetherston et al., 2018). However, this stands in contrast to evidence that perceived control is unlikely to affect job attainment (McGee, 2015). Thus, future research ought to explore feelings of efficacy and locus of control to determine which gives access to more influential sources or aids in job attainment. The current study establishes the structure of TM networks for job seekers, adds influence as an outcome of TM systems, and combines TM and job search 
research. Future studies can take this descriptive evidence to generate tests of the outcomes associated with TM networks.

\section{Limitations and Future Directions}

This cross-sectional study is unable to determine the casual directionality of central variables. TM theory suggests that perceptions of expertise and influence derive from structural, communicative, and relational attributes, but job seekers may assign attributes based on how expert and influential they believe job information sources to be. As with any survey, it is possible that the relationships we propose could be reversed (e.g., perceptions of expertise and influence lead to emotional closeness); however, the cognitive structure revealed by this data is still informative about the TM networks on which job seekers take action because this data is based on sources job seekers actually utilized.

Future research should examine the job search and other TM processes longitudinally. Job seekers tend to engage different sources with varying attributes at different stages of the job search (e.g., applying requires information, interviewing may require coaching; Barbulescu, 2015). It is likely information and influence are differentially required across the job search and attainment processes. Further, TM theory is not only ego-centric, it also has key network tenants. Monge and Contractor (2003) explain that expertise is the first of four steps in a TM system: "expertise recognition, retrieval coordination, directory updating, and information allocation" (p. 199). While TM provides a solid theoretical angle to explore job search, whole network data is needed to fully explicate the theory in this context.

The measures for this study favor psychological evaluation of others and one's network over more-objective network graphs. The benefit of this approach is network actors take action based on their view of the network (Bruggeman, 2016). However, this approach neglects a birds- 
eye-view of the networked environment and may miss meaningful variability in network scope and shape. Future studies are encouraged to include both network perceptions and measurable network attributes rather than one or the other. Additionally, future research could benefit from considering how TM networks evolve to (un)successfully attain expertise and influence.

This paper is not alone in investigating information seeking in socio-technical environments. Ramirez and colleagues (2002) proffer a conceptual model about antecedents, behaviors, and outcomes of seeking information online. The complex and dispersed Web 2.0 environment makes it difficult to apply such a framework. Ramirez et al.'s (2002) model focuses on receiver's intent with regard to information seeking, whereas this study emphasizes actors' perception of a complex information environment. Future research should utilize this information seeking typology with network perceptions to build a more robust understanding of information seeking, job search, and TM. Further, demographic differences (e.g. career field, tenure, age, education, etc.) likely affect how one uses their network (see, Piercy \& Lee, 2019). Future work could benefit from explicitly testing demographic and source differences in socio-technical job search networks and other information seeking processes.

Finally, the expertise measure we adapted was McCroskey and Teven's (1999) source credibility scale. Results showed that each source called on during the job search is perceived to offer expertise. A measure of information quality or knowledge could equally serve as an indicator of expertise. Expertise attainment is likely grounded in complex meaning-making processes. Future research should explore messages and expertise exchange. Further, a logical extension to TM may push the boundaries of the theory by employing other kinds of knowledge and capital transfer measures.

\section{Conclusion}


This study uses a national sample of U.S. job seekers to explore TM theory. Specifically, this study finds that expertise and influence vary based on structural attributes (both source status and bridging ability) and relational attributes (emotional closeness). Frequency of communication was only related to influence. Results extend the domain of TM to include influence. Further, results expand researcher's understanding of the socio-technical job search process and explicate the role of online communication and tie variety during the job search. This study serves as a springboard for future research on the role of networks in job search practices. Further, TM theory stands to benefit from examining how socio-technical information sources allow individuals to leverage additional networked capital, like influence. 


\section{References}

Anderson, C., John, O. P., \& Keltner, D. (2012). The personal sense of power. Journal of Personality, 80, 313-344. https://doi.org/10.1111/j.1467-6494.2011.00734.x

Barbulescu, R. (2015). The strength of many kinds of ties: Unpacking the role of social contacts across stages of the job search process. Organization Science, 26, 1040-1058. https://doi.org/10.1287/orsc.2015.0978

Bruggeman, J. (2016). The strength of varying tie strength: Comment on Aral and van Alstyne. American Journal of Sociology, 121, 1919-1930. https://doi.org/10.1086/686267

Burt, R. S. (1995). Structural holes: The social structure of competition (1st Edition). Cambridge, Mass.: Harvard University Press.

Burt, R. S. (2004). Structural holes and good ideas. American Journal of Sociology, 110, 349399. https://doi.org/10.1086/421787

Contractor, N. S., Monge, P., \& Leonardi, P. M. (2011). Network theory | Multidimensional networks and the dynamics of sociomateriality: Bringing technology inside the network. International Journal of Communication, 5, 682-720.

Fetherston, M., Cherney, M. R., \& Bunton, T. E. (2018). Uncertainty, technology use, and career preparation self-efficacy. Western Journal of Communication, 82, 276-295. https://doi.org10.1080/10570314.2017.124704

Gätcher, S., Starmer, C., \& Tufano, F. (2015). Measuring the closeness of relationships: A comprehensive evaluation of the "Inclusion of the other in the self" scale. PLOS ONE, 10(6), e0129478. https://doi.org/10.1371/journal.pone.0129478 
Gee, L. K., Jones, J., \& Burke, M. (2017). Social networks and labor markets: How strong ties relate to job finding on Facebook's social network. Journal of Labor Economics, 35, 485518. https://doi.org/10.1086/686225

Granovetter, M. S. (1973). The strength of weak ties. American Journal of Sociology, 78, 13601380. https://doi.org/10.1016/b978-0-12-442450-0.50025-0

Granovetter, M. S. (1983). The strength of weak ties: A network theory revisited. Sociological Theory, 1, 201-233. https://doi.org/10.2307/202051

Hollingshead, A. B. (1998). Communication, learning, and retrieval in transactive memory systems. Journal of Experimental Social Psychology, 34, 423-442. https://doi.org/10.1006/jesp.1998.1358

Kotlarsky, J., van den Hooff, B., \& Houtman, L. (2015). Are we on the same page? Knowledge boundaries and transactive memory system development in cross-functional teams. Communication Research, 42, 319-344. https://doi.org/10.1177/0093650212469402

Kramer, M. W., Lee, S. K., \& Guo, Y. (2018). Using communication technology to manage uncertainty during organizational assimilation: Information-seeking and informationgiving. Western Journal of Communication, 304-325. https://doi.org/10.1080/10570314.2018.1518538

Kwahk, K. Y., \& Park, D. H. (2018). Leveraging your knowledge to my performance: The impact of transactive memory capability on job performance in a social media environment. Computers in Human Behavior, 80, 314-330. https://doi.org/ 10.1016/j.chb.2017.10.047 
Lee, J.-Y., Bachrach, D. G., \& Lewis, K. (2014). Social network ties, transactive memory, and performance in groups. Organization Science, 25, 951-967. https://doi.org/10.1287/orsc.2013.0884

Lee, S. K., Kim, H., \& Piercy, C. W. (2019). The role of status differentials and homophily in the formation of social support networks of a voluntary organization. Communication Research, 46, 208-235. https://doi.org/10.1177/0093650216641501

Lin, N. (2001). Social capital: A theory of social structure and action. New York: Cambridge University Press.

Lin, N., Ensel, W. M., \& Vaughn, J. C. (1981). Social resources and strength of ties: Structural factors in occupational status attainment. American Sociological Review, 46, 393-405. https://doi.org/10.2307/2095260

Lin, N., Lee, H. Y., \& Ao, D. (2014). Contact status and finding a job: Validation and extension. In N. Lin, Y. C. Fu, \& C.-J. J. Chen (Eds.), Social capital and its institutional contingencies: A study of the United States, China, and Taiwan (pp. 21-41). New York: Routledge.

March, J. G., \& Simon, H. A. (1958). Organizations. Oxford: Wiley.

Marin, A. (2012). Don't mention it: Why people don't share job information, when they do, and why it matters. Social Networks, 34, 181-192. https://doi.org/10.1016/j.socnet.2011.11.002

Marsden, P. V., \& Gorman, E. H. (2001). Social networks, job changes, and recruitment. In I. Berg \& A. L. Kalleberg (Eds.), Sourcebook of labor markets: Evolving structures and processes (pp. 467-502). Boston, MA: Springer US. https://doi.org/10.1007/978-1-46151225-7_19 
McCarty, C., Killworth, P. D., Bernard, H. R., Johnsen, E. C., \& Shelley, G. A. (2001).

Comparing two methods for estimating network size. Human Organization, 60, 28-39. https://doi.org/10.17730/humo.60.1.efx5t9gjtgmga73y

McCroskey, J. C., \& Teven, J. J. (1999). Goodwill: A reexamination of the construct and its measurement. Communication Monographs, 66, 90-103.

https://doi.org/10.1080/03637759909376464

McGee, A. D. (2015). How the perception of control influences unemployed job search. ILR Review, 68, 184-211. https://doi.org/10.1177/0019793914556245

Monge, P., \& Contractor, N. S. (2003). Theories of communication networks. New York: Oxford University Press.

Operario, D., Adler, N. E., \& Williams, D. R. (2004). Subjective social status: Reliability and predictive utility for global health. Psychology \& Health, 19, 237-246. https://doi.org/10.1080/08870440310001638098

Peltokorpi, V. (2008). Transactive memory systems. Review of General Psychology, 12, 378394. https://doi.org/10.1037/1089-2680.12.4.378

Piercy, C. W., \& Lee, S. K. (2019). A typology of job search sources: Exploring the changing nature of job search networks. New Media \& Society, 21, 1173-1191. https://doi.org/10.1177/1461444818808071

Pinheiro, J., Bates, D., DebRoy, S., Sarkar, D., \& R Core Team. (2018). nmle: Linear and Nonlinear Mixed Effects Models [R package version 3.1-137].

Putnam, R. D. (2001). Bowling alone: The collapse and revival of American community. New York: Simon and Schuster. 
Ramirez, A., Walther, J. B., Burgoon, J. K., \& Sunnafrank, M. (2002). Information-seeking strategies, uncertainty, and computer-mediated communication: Toward a conceptual model. Human Communication Research, 28, 213-228. https://doi.org/10.1111/j.14682958.2002.tb00804.x

Rouse, S. V. (2015). A reliability analysis of Mechanical Turk data. Computers in Human Behavior, 43, 304-307. https://doi.org/10.1016/j.chb.2014.11.004

Rosseel, Y. (2012). lavaan: An R package for structural equation modeling. Journal of Statistical Software, 48, 1-36. https://doi.org/10.18637/jss.v048.i02

Rozzell, B., Piercy, C. W., Carr, C. T., King, S., Lane, B. L., Tornes, M., ... Wright, K. B. (2014). Notification pending: Online social support from close and nonclose relational ties via Facebook. Computers in Human Behavior, 38, 272-280. https://doi.org/10.1016/j.chb.2014.06.006

Sheehan, K. B. (2018). Crowdsourcing research: data collection with Amazon's Mechanical Turk. Communication Monographs, 85, 140-156. https://doi.org/10.1080/03637751.2017.1342043

Smith, S. S. (2012). Why weak ties' help and strong ties' don't: Reconsidering why tie strength matters. Retrieved from https://escholarship.org/uc/item/15p921r5

Sparrow, B., Liu, J., \& Wegner, D. M. (2011). Google effects on memory: Cognitive consequences of having information at our fingertips. Science, 1207745. https://doi.org/10.1126/science.1207745

Treem, J. W. (2012). Communicating expertise: Knowledge performances in professionalservice firms. Communication Monographs, 79, 23-47. https://doi.org/10.1080/03637751.2011.646487 
Treem, J. W., \& Leonardi, P. M. (2016). What is expertise? Who is and expert? Some definitive answers. In J. W. Treem \& P. M. Leonardi (Eds.), Expertise, communication, and organizing (pp. 1-24). New York, NY: Oxford University Press.

Treem, J. W., \& Leonardi, P. M. (2017). Recognizing expertise: Factors promoting congruity between individuals' perceptions of their own expertise and the perceptions of their coworkers. Communication Research, 44, 198-224. https://doi.org/10.1177/0093650215605154

van Hoye, G., van Hooft, E., \& Lievens, F. (2009). Networking as a job search behaviour: A social network perspective. Journal of Occupational and Organizational Psychology, 82, 661-682. https://doi.org/ 10.1348/096317908X360675

Wegner, D. M. (1987). Transactive memory: A contemporary analysis of group mind. In Theories of group behavior (pp. 185-208). New York: Springer.

Yuan, Y. C., Fulk, J., Monge, P. R., \& Contractor, N. S. (2010). Expertise directory development, shared task interdependence, and strength of communication network ties as multilevel predictors of expertise exchange in transactive memory work groups.

Communication Research, 37(1), 20-47. https://doi.org/10.1177/0093650209351469

${ }^{1}$ Like many communication, psychology, and sociology researchers we adopt a bounded rationality perspective (March \& Simon, 1958). Specifically, we assume that individuals operate with a finite and imperfect set of information, assumptions, ability, and time when approaching a complex problem like job search. 
Table 1

Means, SDs, and Grand Mean-Based Bivariate Correlations Among Study Variables

\begin{tabular}{|c|c|c|c|c|c|c|c|c|c|}
\hline Variable & $M$ & $S D$ & 1. & 2. & 3. & 4. & 5. & 6. & 7. \\
\hline 1. Expertise & 5.60 & 1.08 & 1.00 & & & & & & \\
\hline 2. Influence & 4.35 & 1.51 & 0.40 & 1.00 & & & & & \\
\hline 3. Source status & 6.10 & 1.74 & 0.44 & 0.35 & 1.00 & & & & \\
\hline 4. Network closure & 0.35 & 0.17 & 0.06 & 0.04 & 0.04 & 1.00 & & & \\
\hline 5. Bridging ability & 5.19 & 1.20 & 0.46 & 0.58 & 0.32 & 0.02 & 1.00 & & \\
\hline $\begin{array}{l}\text { 6. Frequency of } \\
\text { Interaction }\end{array}$ & 5.56 & 1.76 & 0.09 & -0.20 & -0.01 & 0.03 & 0.07 & 1.00 & \\
\hline 7. Closeness & 3.34 & 1.71 & 0.21 & -0.00 & 0.04 & 0.00 & 0.08 & 0.51 & 1.00 \\
\hline
\end{tabular}

Note: Correlations based on pooled Grand Means. All correlations greater than .09 are significant at $p<.001$, values from .07 to .09 are $p<.01, N=1297$. Because correlation values and direction often vary by source-type, signs in the MLM may differ from this table. 
Table 2

Multilevel Model Predicting Expertise

\begin{tabular}{|c|c|c|c|c|c|c|c|c|c|c|c|c|}
\hline \multirow[b]{2}{*}{ Fixed Effects } & \multicolumn{2}{|c|}{ Intercept only } & \multicolumn{2}{|c|}{ Model 1 (H1) } & \multicolumn{2}{|c|}{ Model 2 (RQ1) } & \multicolumn{2}{|c|}{ Model 3 (H3) } & \multicolumn{2}{|c|}{ Model 4 (H4) } & \multicolumn{2}{|c|}{ Model 5 (H5) } \\
\hline & $\begin{array}{l}\text { Estimate } \\
\text { (SE) }\end{array}$ & $t$-value & $\begin{array}{l}\text { Estimate } \\
\text { (SE) }\end{array}$ & $t$-value & $\begin{array}{l}\text { Estimate } \\
\text { (SE) }\end{array}$ & $t$-value & $\begin{array}{l}\text { Estimate } \\
\text { (SE) }\end{array}$ & $t$-value & $\begin{array}{l}\text { Estimate } \\
\text { (SE) }\end{array}$ & $t$-value & $\begin{array}{l}\text { Estimate } \\
\text { (SE) }\end{array}$ & $t$-value \\
\hline Intercept & $5.59(0.07)$ & $85.77^{* * *}$ & $5.61(0.06)$ & $88.26^{* * *}$ & $5.54(0.10)$ & $53.17^{* * *}$ & $5.53(0.10)$ & $52.39^{* * *}$ & $5.54(0.11)$ & $52.65^{* * *}$ & $5.54(0.10)$ & $56.41^{* * * *}$ \\
\hline Source Status & & & $0.27(0.02)$ & $17.08^{* * *}$ & $0.27(0.02)$ & $17.06^{* * *}$ & $0.22(0.02)$ & $14.59^{* * *}$ & $0.22(0.02)$ & $14.62^{* * *}$ & $0.22(0.02)$ & $14.69^{* * *}$ \\
\hline Network Closure & & & & & $0.23(0.24)$ & 0.97 & $0.23(0.22)$ & 1.05 & $0.22(0.22)$ & 1.03 & $0.23(0.21)$ & 1.08 \\
\hline Bridging Ability & & & & & & & $0.27(0.02)$ & $13.37^{* * *}$ & $0.26(0.02)$ & $13.01^{* * *}$ & $0.26(0.02)$ & $13.09^{* * *}$ \\
\hline $\begin{array}{l}\text { Frequency of } \\
\text { interaction }\end{array}$ & & & & & & & & & $-0.02(0.02)$ & -1.42 & $0.03(0.02)$ & 1.94 \\
\hline \multicolumn{13}{|l|}{ Closeness } \\
\hline Random Effects & Estimate & $S D$ & Estimate & $S D$ & Estimate & $S D$ & Estimate & $S D$ & Estimate & $S D$ & Estimate & $S D$ \\
\hline Participant & 0.38 & 0.62 & 0.31 & 0.56 & 0.30 & 0.56 & 0.25 & 0.50 & 0.25 & 0.50 & 0.24 & 0.49 \\
\hline Source & 0.02 & 0.14 & 0.02 & 0.15 & 0.02 & 0.15 & 0.04 & 0.20 & 0.04 & 0.20 & 0.03 & 0.16 \\
\hline Residual & 0.77 & 0.88 & 0.63 & 0.79 & 0.63 & 0.79 & 0.56 & 0.75 & 0.56 & 0.75 & 0.54 & 0.74 \\
\hline \multicolumn{13}{|c|}{ Model Summary } \\
\hline Log-likelihood & \multicolumn{2}{|c|}{-1841.41} & \multicolumn{2}{|c|}{-1721.97} & \multicolumn{2}{|c|}{-1709.45} & \multicolumn{2}{|c|}{-1626.62} & \multicolumn{2}{|c|}{-1625.62} & \multicolumn{2}{|c|}{-1605.40} \\
\hline AIC & \multicolumn{2}{|c|}{3690.81} & \multicolumn{2}{|c|}{3451.96} & \multicolumn{2}{|c|}{3430.91} & \multicolumn{2}{|c|}{3253.25} & \multicolumn{2}{|c|}{3251.24} & \multicolumn{2}{|c|}{3228.80} \\
\hline Chi-Square $\Delta$ & & & \multicolumn{2}{|c|}{$262.96^{* * *}$} & \multicolumn{2}{|c|}{0.94} & \multicolumn{2}{|c|}{$165.66^{* * *}$} & \multicolumn{2}{|c|}{2.01} & \multicolumn{2}{|c|}{$40.44^{* * *}$} \\
\hline
\end{tabular}

Note: $N=285$ participants, 1297 sources. Model improvement is indicated by significant improvement in Chi-Square LRT, ${ }^{* * *} p<.001,{ }^{* * *} p<.01,{ }^{*} p<.05$ 
Table 3

Multilevel Model Predicting Influence

\begin{tabular}{|c|c|c|c|c|c|c|c|c|c|c|c|c|}
\hline \multirow[b]{2}{*}{ Fixed Effects } & \multicolumn{2}{|c|}{ Intercept only } & \multicolumn{2}{|c|}{ Model 1 (H2) } & \multicolumn{2}{|c|}{ Model 2 (RQ2) } & \multicolumn{2}{|c|}{ Model 3 (RQ3) } & \multicolumn{2}{|c|}{ Model $4(R Q 4)$} & \multicolumn{2}{|c|}{ Model 5 (H6) } \\
\hline & $\begin{array}{l}\text { Estimate } \\
(\mathrm{SE})\end{array}$ & $t$-value & $\begin{array}{l}\text { Estimate } \\
(\mathrm{SE})\end{array}$ & $t$-value & $\begin{array}{l}\text { Estimate } \\
(\mathrm{SE})\end{array}$ & $t$-value & $\begin{array}{l}\text { Estimate } \\
(\mathrm{SE})\end{array}$ & $t$-value & $\begin{array}{l}\text { Estimate } \\
(\mathrm{SE})\end{array}$ & $t$-value & $\begin{array}{l}\text { Estimate } \\
\text { (SE) }\end{array}$ & $t$-value \\
\hline Intercept & $4.36(0.19)$ & $22.77^{* * *}$ & $4.37(0.18)$ & $24.53^{* * *}$ & $4.34(0.20)$ & $21.55^{* * *}$ & $4.33(0.21)$ & $20.22^{* * *}$ & $4.30(0.20)$ & $21.37^{* * *}$ & $4.30(0.20)$ & $21.50^{* * *}$ \\
\hline Source Status & & & $0.28(0.02)$ & $13.06^{* * *}$ & $0.28(0.02)$ & $13.05^{* * *}$ & $0.22(0.02)$ & $10.49^{* * *}$ & $0.22(0.02)$ & $10.54^{* * *}$ & $0.22(0.02)$ & $10.44^{* * *}$ \\
\hline Network Closure & & & & & $0.11(0.27)$ & 0.42 & $0.11(0.24)$ & 0.45 & $0.14(0.24)$ & 0.56 & $0.15(0.24)$ & 0.62 \\
\hline Bridging Ability & & & & & & & $0.35(0.03)$ & $12.30^{* * *}$ & $0.37(0.03)$ & $12.89^{* * *}$ & $0.37(0.03)$ & $12.90^{* * *}$ \\
\hline $\begin{array}{l}\text { Frequency of } \\
\text { interaction }\end{array}$ & & & & & & & & & $0.10(0.02)$ & $4.50^{* * *}$ & $0.13(0.03)$ & $5.26^{* * *}$ \\
\hline \multicolumn{13}{|l|}{ Closeness } \\
\hline Random Effects & Estimate & $S D$ & Estimate & $S D$ & Estimate & $S D$ & Estimate & $S D$ & Estimate & $S D$ & Estimate & $S D$ \\
\hline Participant & 0.29 & 0.53 & 0.25 & 0.50 & 0.25 & 0.50 & 0.17 & 0.41 & 0.18 & 0.43 & 0.17 & 0.41 \\
\hline Source & 0.34 & 0.58 & 0.29 & 0.54 & 0.29 & 0.54 & 0.37 & 0.61 & 0.31 & 0.56 & 0.31 & 0.56 \\
\hline Residual & 1.58 & 1.26 & 1.40 & 1.18 & 1.40 & 1.18 & 1.29 & 1.13 & 1.26 & 1.12 & 1.26 & 1.12 \\
\hline \multicolumn{13}{|c|}{ Model Summary } \\
\hline Log-likelihood & \multicolumn{2}{|c|}{-2237.33} & \multicolumn{2}{|c|}{-2157.15} & \multicolumn{2}{|c|}{-2157.06} & \multicolumn{2}{|c|}{-2086.55} & \multicolumn{2}{|c|}{-2076.65} & \multicolumn{2}{|c|}{-2072.86} \\
\hline AIC & \multicolumn{2}{|c|}{4482.65} & \multicolumn{2}{|c|}{4324.30} & \multicolumn{2}{|c|}{4326.13} & \multicolumn{2}{|c|}{4187.11} & \multicolumn{2}{|c|}{4169.30} & \multicolumn{2}{|c|}{4163.72} \\
\hline Chi-Square $\Delta$ & & & \multicolumn{2}{|c|}{$160.35^{* * *}$} & \multicolumn{2}{|c|}{0.17} & \multicolumn{2}{|c|}{$141.02^{* * * *}$} & \multicolumn{2}{|c|}{$19.80^{* * *}$} & \multicolumn{2}{|c|}{$7.57^{* *}$} \\
\hline
\end{tabular}

\footnotetext{
Note: $N=285$ participants, 1297 sources. Model improvement is indicated by significant improvement in Chi-Square LRT, ${ }^{* * *} p<.001,{ }^{* * *} p<.01,{ }^{*} p<.05$
} 
Table 4

Means and SDs for Expertise and Influence by Source Type $(N=285)$

\begin{tabular}{|c|c|c|c|c|c|}
\hline & \multirow[b]{2}{*}{$n$} & \multicolumn{2}{|c|}{ Expertise } & \multicolumn{2}{|c|}{ Influence } \\
\hline & & Mean & $S D$ & Mean & $S D$ \\
\hline Strong Online & 120 & 5.76 & 1.07 & $4.30^{\mathrm{c}, \mathrm{d}}$ & 1.51 \\
\hline $\begin{array}{l}\text { Strong In- } \\
\text { Person }\end{array}$ & 130 & 5.63 & 1.07 & $4.18^{\mathrm{f}, \mathrm{g}}$ & 1.45 \\
\hline Weak Online & 136 & $5.90^{\mathrm{a}}$ & 0.96 & $4.66^{\mathrm{e}}$ & 1.31 \\
\hline Weak In-Person & 124 & $5.85^{\mathrm{b}}$ & 1.05 & $4.71^{\mathrm{h}}$ & 1.36 \\
\hline Websites & 261 & $5.43^{\mathrm{a}, \mathrm{b}}$ & 1.99 & $3.41^{\mathrm{c}, \mathrm{e}, \mathrm{f}, \mathrm{h}, \mathrm{i}}$ & 1.46 \\
\hline $\begin{array}{l}\text { Job } \\
\text { boards/listservs }\end{array}$ & 89 & $5.31^{\mathrm{a}, \mathrm{b}}$ & 0.97 & $3.30^{c, e, f, h, i, j}$ & 1.36 \\
\hline $\begin{array}{l}\text { Employment } \\
\text { agencies }\end{array}$ & 65 & 5.44 & 1.06 & $4.71^{i, j}$ & 1.17 \\
\hline Career fairs & 45 & 5.76 & 1.19 & $4.43^{\mathrm{i}, \mathrm{j}, \mathrm{k}}$ & 1.05 \\
\hline $\begin{array}{l}\text { Direct online } \\
\text { application }\end{array}$ & 205 & 5.55 & 1.16 & $5.04^{\mathrm{d}, \mathrm{g}, \mathrm{i}, \mathrm{j}}$ & 1.36 \\
\hline $\begin{array}{l}\text { Direct In- } \\
\text { Person } \\
\text { Application }\end{array}$ & 122 & 5.55 & 1.24 & $5.21^{\mathrm{d}, \mathrm{g}, \mathrm{i}, \mathrm{j}, \mathrm{k}}$ & 1.19 \\
\hline
\end{tabular}

Note: In this table "strong" represents close friends or family members, "weak" represents acquaintances or professional contacts. Significant differences (using Bonferroni correction at $p$ $<.05)$ between rows are marked by superscript letters. 